\title{
Lord Zuckerman Defends His Position
}

LORD ZUCKERMAN launched a counter attack on the scientific community this week, defending his policy of parsimony in cancer research (see Nature, 240, 4; 1972). At a meeting of the British Association for Cancer Research, Lord Zuckerman claimed that because of the narrow mindedness of the scientific community, the "galvanizing ideas" of less well-established scientists may be wasted.

Members of the association attending this meeting were visibly self-conscious in the face of the recent massive cancer campaign launched in the United States. But if there is to be no loosening of purse strings on this side of the Atlantic, at least it is clear that British cancer research is likely to benefit from the recent improvement in the organization of existing facilities. Thanks to the MRC Coordinating Committee on Cancer Research, represented at the meeting by its chairman, Lord Rosenheim, unnecessary duplication of research is now being eliminated. The emergence of oncology as a discipline in its own right, moreover, is signalled by the institution of two academic chairs in clinical oncology, financed by the Imperial Cancer Research Fund and the Cancer Research Campaign at St Bartholomews and the Royal Marsden hospitals respectively. Lord Nathan, of the Cancer Research Campaign, announced that five more chairs carrying life tenure would be established on funds from the CRC sometime in the future.

Of the estimated $£ 6$ million in public funds spent annually on cancer research, some will now be spent on pilot oncological centres attached to four hospitals. These centres are to be financed jointly by the MRC and the Department of Health and Social Security.

One of the expected advantages of these regional centres is that they will encourage greater understanding and collaboration between basic scientists and clinicians. They will also promote the training of and provide the experience for "career scientists" specifically in oncology. Both Lord Rosenheim and Professor E. Scowen (ICRF) insisted on the need for career scientists in oncology.

As to the direction in which such hypothetical career scientists should be pointed, Professor Sir David Smithers (Royal Marsden Hospital) rose to the attack of the subcellular approach.
Supracellular biologists, he maintained, have made a far greater contribution to the progress of cancer therapy than molecular biologists. In this connexion, Mr Benno Schmidt, of the US National Program for the Conquest of Cancer, confessed that the $\$ 51$ million program of virus research in the United States is now "under the supervision of a panel" which is to decide whether it has reached a point of diminishing returns. The silence from the molecular biologists present at the meeting was deafening.

Lord Zuckerman said that money "obviously will buy brains",- what it

\section{EUROPEAN TECHNOLOGY \\ IIY IO SIRBgei}

from a Correspondent

THE basic problems associated with the development of an integrated European research and development programme are essentially those of decision making at the management level. This was the basis of Professor Hermann Bondi's Stevenson Memorial Lecture delivered at the London School of Economics last week.

Management is essentially the science of human relationships, Professor Bondi said, and he illustrated the necessity of delegation by governments by contrasting the smooth progress of the European Space Research Organization (ESRO) with the ill-fated Europa Launcher Development Organization (ELDO). No rocketry is involved in ESRO (the satellites are launched by an American carrier), and the governments involved are prepared to delegate management and planning decisions to the ESRO organization itself. But although ELDO is based on a liquid-fuel rocket (which is of virtually no military use), it does involve concepts of "defence", so there has been no delegation and the organization is supposed to be run by a secretariat which has no executive powers. The contracts are divided among participant countries on the basis both of tasksharing and of cost-sharing, and this has resulted in "perfect machinery for escalation".

The arguments in favour of international cooperation are well known; less proliferation of advanced products and research institutions means better staffing of those institutions which remain. The difficulties, said Professor will not buy, however, is original ideas. Lord Zuckerman, it seems, has been receiving large numbers of letters since his report on funding of cancer research was published at the end of October. These letters are from people who have had difficulty in getting their original ideas taken seriously by the oncological establishment. Lord Zuckerman refused to commit himself on the value of their ideas which, he said, he was not qualified to judge. But someone has to. With limited funds, selection must necessarily be rigorous and Lord Zuckerman can undoubtedly expect many more letters.

Bondi, are basically those of human relationships and applied psychology. Practical matters such as the principle of fair returns (that is, that a participant country should receive contracts roughly in proportion to its investment in the project) can in fact be solved fairly easily-by awarding more contracts to international consortia, so that the cooperation in fact takes place at the industrial level and not merely at the governmental level.

The real difficulty arises with international decision making. The scientific advisers to any government, said Professor Bondi, are liable to be appointed on a fairly ad hoc basis. Decision making is often a matter of choice between two almost equally suitable alternatives, and what matters is that a decision should be made swiftly rather than the nature of the decision itself. If, however, the advisers of one country suggest one course of action while those of another suggest a different one, "national policies" may be formed, even though there may be little to choose between the two proposals on objective grounds, and valuable time may be lost. The answer is clearly that there should be an international scientific advisory body for such projects.

Other problems of a practical nature - the differing trends in industrial development in the member countries, the necessity for "slimming down" duplicated effort, and of deciding which establishments are to be sacrificed in the process, are seen by Professor Bondi as a necessity painful to national interests that can only be solved without undue anguish by the companies concerned cooperating and producing an integrated European technology. 